Article

\title{
Improvement in Surface Solar Irradiance Estimation Using HRV/MSG Data
}

\author{
Filomena Romano ${ }^{1, *(1)}$, Domenico Cimini ${ }^{1,2}$ (1) , Angela Cersosimo ${ }^{1}$, Francesco Di Paola ${ }^{1}$ (D), \\ Donatello Gallucci $^{1}$ (1) , Sabrina Gentile ${ }^{1,2}$, Edoardo Geraldi ${ }^{1,3}$ (1D), Salvatore Larosa ${ }^{1}$ (1) \\ Saverio T. Nilo ${ }^{1}$ (D), Elisabetta Ricciardelli ${ }^{1}$, Ermann Ripepi ${ }^{1}$ (D) and Mariassunta Viggiano $^{1}$ (iD \\ 1 Institute of Methodologies for Environmental Analysis, National Research Council (IMAA/CNR), \\ 85100 Potenza, Italy; domenico.cimini@imaa.cnr.it (D.C.); angela.cersosimo@imaa.cnr.it (A.C.); \\ francesco.dipaola@imaa.cnr.it (F.D.P.); donatello.gallucci@imaa.cnr.it (D.G.); \\ sabrina.gentile@imaa.cnr.it (S.G.); edoardo.geraldi@cnr.it (E.G.); salvatore.larosa@imaa.cnr.it (S.L.); \\ saverio.nilo@imaa.cnr.it (S.T.N.); elisabetta.ricciardelli@imaa.cnr.it (E.R.); ermann.ripepi@imaa.cnr.it (E.R.); \\ mariassunta.viggiano@imaa.cnr.it (M.V.) \\ 2 Center of Excellence Telesensing of Environment and Model Prediction of Severe events (CETEMPS), \\ University of L'Aquila, 67100 L'Aquila, Italy \\ 3 Institute for Archaeological and Monumental Heritage, National Research Council (IBAM/CNR), \\ 85100 Potenza, Italy \\ * Correspondence: filomena.romano@imaa.cnr.it; Tel.: +39-0971-427266
}

Received: 10 July 2018; Accepted: 13 August 2018; Published: 15 August 2018

\begin{abstract}
The Advanced Model for the Estimation of Surface Solar Irradiance (AMESIS) was developed at the Institute of Methodologies for Environmental Analysis of the National Research Council of Italy (IMAA-CNR) to derive surface solar irradiance from SEVIRI radiometer on board the MSG geostationary satellite. The operational version of AMESIS has been running continuously at IMAA-CNR over all of Italy since 2017 in support to the monitoring of photovoltaic plants. The AMESIS operative model provides two different estimations of the surface solar irradiance: one is obtained considering only the low-resolution channels (SSI_VIS), while the other also takes into account the high-resolution HRV channel (SSI_HRV). This paper shows the difference between these two products against simultaneous ground-based observations from a network of 63 pyranometers for different sky conditions (clear, overcast and partially cloudy). Comparable statistical scores have been obtained for both AMESIS products in clear and cloud situation. In terms of bias and correlation coefficient over partially cloudy sky, better performances are found for SSI_HRV $\left(0.34 \mathrm{~W} / \mathrm{m}^{2}\right.$ and 0.995 , respectively) than SSI_VIS $\left(-33.69 \mathrm{~W} / \mathrm{m}^{2}\right.$ and 0.862$)$ at the expense of the greater run-time necessary to process HRV data channel.
\end{abstract}

Keywords: solar irradiance; MSG; SEVIRI; HRV; AMESIS

\section{Introduction}

The deployment and optimization of photovoltaic system plants require accurate knowledge of the temporal and spatial variability of surface solar radiation, which is directly linked to solar energy production. The characterization of the temporal and spatial distribution of surface solar irradiance is very challenging due to cloud presence and, in complex orography, to shadowing and altitude/slope effects [1,2]. Clouds play a major role in the Earth-atmosphere system, affecting the incoming solar and outgoing thermal energy with interactions with the other atmospheric components. Clouds absorb and even more scatter radiation in the shortwave part of the spectrum, they absorb radiation in the longwave part (which is emitted by Earth's surface and lower troposphere) and they 
reemit it downwards and into space [3]. It is very difficult to estimate the radiative effects of clouds accurately, due to their high temporal and spatial variability. Ideally, in situ measurements provide the best method for obtaining solar irradiance estimation at surface [4], but the network of these ground instruments is not sufficiently dense [5,6]; therefore, methods involving extrapolation statistics based on surface measurements or satellite observations are commonly exploited to complement ground-based measurements and cover areas with no ground instruments installed [7-9]. The geostationary orbit covers the Earth's surface with a high time resolution, but its weakness is the increase in the pixel apparent size with latitude and longitude. By contrast, polar satellites, rotating at a much lower altitude, have a higher spatial resolution but a restricted temporal coverage. Therefore, only geostationary data allow the diurnal cycle of the solar irradiance at the Earth's surface to be captured. However, the availability of satellite-derived solar radiation measurements has often proven to be spatially and temporally inadequate for many applications [10]; in particular, broken clouds are difficult to detect, especially small clouds that can make the solar surface irradiance estimation less accurate [11]. At present, many different methods are exploited for solar radiation mapping, including the interpolation of surface measurements and the orographic downscaling of satellite data [10,12-14]. The accuracy and the suitability of interpolation and orographic downscaling approaches for complex-orography regions are still under study. In recent years, several parametric, look-up table (LUT), and statistical methods have been developed to retrieve the surface solar irradiance from satellite observations. Parametric methods estimate the surface solar irradiance relying on the parameterization of surface and atmospheric variables [15-17]. One weakness of these methods resides in the spatial and temporal variability of some variables, especially cloud, aerosol, and water vapor distribution. Look-up table methods are based on a pre-established radiative-transfer database, and have been shown to give satisfactory results [18-22]. In addition, hybrid methods have been extensively used. Hybrid methods combine the robustness of a physical approach, based on radiative transfer models, with a simplified cloud/aerosol model using a cloud index. Thus, the clear-sky solar irradiance is firstly computed by means of a LUT or a radiative transfer model, then it is used to compute the cloudy solar irradiance depending upon a cloud index derived from satellite observations [23-25]. Also, artificial neural networks (ANN) have been employed to estimate solar irradiation using different sets of inputs [26-28]. The study presented in [29] developed an ANN to retrieve solar radiation with hourly cloud parameters derived by combining low-Earth-orbit observations (from MODIS) with geostationary imagery (from Multifunctional Transport Satellite, MTSAT).

Cloudy and cloud-free satellite pixels must be distinguished before the estimation of solar irradiance surface. The main difficulties in cloud detection are due to the reduced cloud-surface contrast [30]. To improve cloud detection from satellite observations, many efforts have been made and different methods have been proposed. Most of the techniques based on satellite image algorithms use the threshold method [31-36] or statistical procedures [37,38]. Artificial intelligence techniques are increasingly being used in areas of prediction and classification, these algorithms are robust and very flexible $[39,40]$. In the last few years, the Spinning Enhanced Visible and InfraRed Imager (SEVIRI) High-Resolution Visible (HRV) channel on board the Meteosat Second Generation (MSG) has been used for solar irradiance estimation [41,42] and short-term forecasting [43].

This work focuses on the improvement of the spatial resolution of surface solar irradiance by using higher-resolution imaging; this allows us to avoid downscaling techniques to achieve $\sim 1 \mathrm{~km}$ and, at the same time, to apply downscaling techniques starting from $\sim 1 \mathrm{~km}$ when higher spatial resolution is required. In this work, we use observations from the SEVIRI. Solar radiance varies rapidly in time and space and therefore requires instruments with high spatial and temporal resolution. Among the operational instruments in Europe, the most suitable temporal and spatial resolution trade-off is from SEVIRI on MSG-4 $\left(0^{\circ} \mathrm{N}, 0^{\circ} \mathrm{E}\right)$. SEVIRI images are also available at higher temporal resolution (5 min) through the Rapid Scanning Service (RSS) from MSG-3 $\left(0^{\circ} \mathrm{N}, 9.5^{\circ} \mathrm{E}\right)$. The Advanced Model for the Estimation of Surface Solar Irradiance (AMESIS) [19] operative model (described in the following sections) that we have developed is able to produce surface solar irradiance using both the IR-VIS 
and IR-VIS + HRV SEVIRI channel combinations. The implementation of AMESIS on RSS images is currently under development. However, this would not improve the spatial resolution, which is the main focus of this work. Similarly, benefits are expected from the ever-increasing spatial resolution of new and future satellite instruments, e.g., the Flexible Combined Imager (FCI) on the Meteosat Third Generation series planned from 2021 onwards. The SEVIRI High-Resolution Visible (HRV) channel is able to resolve sub-pixel clouds not detectable by the other SEVIRI VIS channels. The main purpose of this paper is to understand whether the use of the HRV channel at a higher resolution can improve the accuracy of the solar irradiance estimation in particular over partially cloudy sky. The paper shows a comparison between these two products against ground-based in situ observations.

\section{Data and Methods}

The SEVIRI instrument is designed to support numerical weather forecasting and nowcasting over Europe and Africa [44,45]. The SEVIRI radiometer is the main payload on board the MSG geostationary satellite series, operated by the European Organization for the Exploitation of Meteorological Satellites (EUMETSAT). The MSG satellites—namely, Meteosat-8, -9, -10 and -11—operate over Europe, Africa and the Indian Ocean in geostationary orbit $36,000 \mathrm{~km}$ above the equator. SEVIRI, a 50-cm-diameter aperture line-by-line scanning radiometer, has twelve spectral channels, eleven at low and one at high spatial resolution. The low spatial resolution channels are in infrared and visible bands, with a spatial sampling of $3 \mathrm{~km}$ and an actual instantaneous field of view leading to a spatial resolution of about $4.8 \mathrm{~km}$ at the sub-satellite point (SSP). The high spatial resolution channel, the HRV, is a broadband $(0.3-1.1 \mu \mathrm{m})$ channel with a spatial sampling of $1 \mathrm{~km}$ and an actual instantaneous field of view leading to spatial resolution of about $1.67 \mathrm{~km}$ at the SSP. The HRV images are acquired on a reduced Earth area.

A ground-based pyranometer network is deployed and maintained by the regional agency for environmental protection (ARPA) of Lombardy region in Italy (http:/ / www.arpalombardia.it/). ARPA Lombardia performs data acquisition, processing and quality control at either 10 or $60 \mathrm{~min}$ temporal intervals. The network consists of 63 pyranometers manufactured by Kippen and Zonen. The instrument specification states $\sim 3 \%$ measurement uncertainty. Overall instrument maintenance is performed every $\sim 2$ years. Following WMO guidelines, automatic data quality tests have been implemented by ARPA Lombardia [46,47]. The pyranometer stations reported in Table 1 are located at different altitudes (see Figure 1).

Table 1. Identity code (ID), location, and altitude of ground observation stations.

\begin{tabular}{cccccccc}
\hline ID_Station & Latitude & Longitude & Altitude $(\mathbf{m})$ & ID_Station & Latitude & Longitude & Altitude $(\mathbf{m})$ \\
\hline 132 & 45.659851 & 19.659089 & 211 & 1347 & 45.950001 & 9.4600000 & 1713 \\
146 & 46.013573 & 9.6624260 & 1824 & 110 & 44.963810 & 10.767801 & 22 \\
595 & 45.633198 & 9.5564108 & 190 & 139 & 45.156864 & 10.797858 & 19 \\
586 & 45.826481 & 10.097358 & 192 & 214 & 45.187836 & 10.887401 & 15 \\
847 & 46.040707 & 9.7975283 & 1954 & 148 & 45.547844 & 8.8476763 & 182 \\
1360 & 45.885708 & 9.9469538 & 564 & 166 & 45.157330 & 10.824207 & 25 \\
119 & 45.881668 & 9.6473770 & 700 & 695 & 45.412109 & 10.683630 & 113 \\
129 & 46.025890 & 10.342786 & 362 & 671 & 45.151348 & 10.860067 & 22 \\
596 & 45.620644 & 9.6118517 & 182 & 100 & 45.496109 & 9.2578459 & 120 \\
1077 & 45.880001 & 9.7700005 & 1138 & 102 & 45.186337 & 9.4865770 & 140 \\
1325 & 45.810440 & 10.375551 & 1068 & 140 & 45.281292 & 8.9889202 & 100 \\
1365 & 45.673401 & 10.340300 & 911 & 147 & 45.541992 & 9.2059374 & 142 \\
1367 & 45.877102 & 10.447216 & 775 & 502 & 45.472557 & 9.2226477 & 122 \\
134 & 45.433056 & 10.039325 & 93 & 620 & 45.470985 & 9.1894445 & 122 \\
145 & 45.891499 & 10.188790 & 222 & 106 & 44.823254 & 9.1953688 & 500 \\
846 & 46.174320 & 10.471110 & 2108 & 114 & 45.320095 & 9.2646246 & 88 \\
1075 & 46.169319 & 10.341660 & 659 & 125 & 45.232506 & 8.6830683 & 106 \\
1366 & 46.038010 & 9.1413231 & 291 & 512 & 45.671303 & 9.2342949 & 250 \\
1378 & 45.750465 & 10.736627 & 291 & 642 & 45.194016 & 9.1649857 & 77 \\
136 & 45.162968 & 10.059123 & 44 & 672 & 45.039421 & 8.9145050 & 74 \\
141 & 45.717659 & 9.0858936 & 310 & 133 & 46.105179 & 9.5694208 & 800 \\
150 & 45.121067 & 10.195482 & 39 & 143 & 46.493744 & 10.207782 & 2320 \\
\hline
\end{tabular}


Table 1. Cont

\begin{tabular}{cccccccc}
\hline ID_Station & Latitude & Longitude & Altitude $(\mathbf{m})$ & ID_Station & Latitude & Longitude & Altitude $(\mathbf{m})$ \\
\hline 629 & 45.365639 & 9.7042618 & 79 & 848 & 46.477097 & 10.205837 & 2660 \\
677 & 45.141880 & 10.044145 & 43 & 836 & 46.147926 & 10.159731 & 1950 \\
1202 & 46.181168 & 9.3250074 & 980 & 1343 & 46.366001 & 9.8999996 & 3032 \\
1303 & 45.109543 & 10.069242 & 36 & 1346 & 46.417400 & 9.3619003 & 1880 \\
109 & 45.260002 & 9.3799944 & 60 & 107 & 46.164913 & 9.8488007 & 307 \\
111 & 45.930000 & 9.4799995 & 1234 & 108 & 46.235424 & 9.4269791 & 206 \\
123 & 45.269161 & 9.5620594 & 67 & 835 & 46.460434 & 10.343612 & 43 \\
127 & 45.701279 & 9.3094740 & 360 & 1273 & 46.240761 & 9.6324825 & 1191 \\
706 & 45.233459 & 9.4002743 & 272 & 1342 & 46.144493 & 9.9752855 & 2440 \\
1266 & 45.233459 & 9.6662951 & 65 & & & & \\
\hline
\end{tabular}
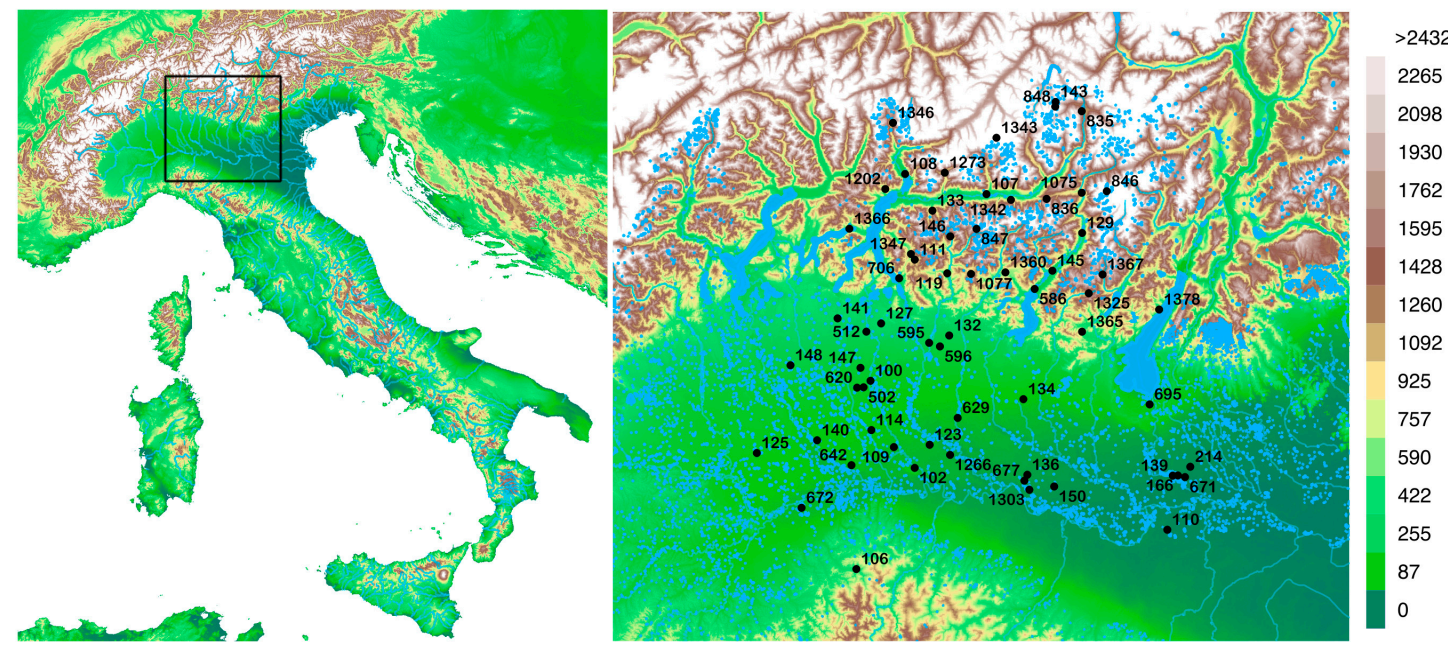

Figure 1. Geographical locations of the used meteorological ground observation stations.

AMESIS is the software package developed at IMAA-CNR that implements and operates the Advanced Model for the Estimation of Surface Solar Irradiance (AMESIS). AMESIS has been running at IMAA-CNR since 2017 in support to photovoltaic plant site monitoring. The operational model is an upgrade of the AMESIS version described in [19]; the new features consist mainly in providing two output products, one obtained using the HRV and the other using the lower resolution channels only. This feature was developed specifically for quantifying the improvements obtainable with the use of the HRV channel.

In this Section, we provide a brief overview of AMESIS, while for further detail we refer to [19]. AMESIS exploits MSG-SEVIRI spectral information (at 15 min resolution) by ingesting the values of radiance and brightness temperature from all SEVIRI channels to estimate surface solar irradiance. The first step of AMESIS consists of classifying the pixels as clear, cloudy, partially cloudy, or affected by aerosol presence $[19,48]$. A cloud phase retrieval is then applied to pixels identified as cloudy or partially cloudy. To this end, the cloud Classification Mask Coupling of Statistical and Physical methods (C_MACSP) algorithm is used [31,49]. C_MACSP, i.e., the cloud mask developed by us, has been validated widely with other operating products and also with 2B-GeoProf (CLOUDSAT Geometrical Profiling Product) [50]. GeoProf is one of the standard products produced by CLOUDSAT, a satellite mission designed to measure the vertical structure of clouds from space. In all the cases, except for those detected as clear after the first step, the model retrieves the microphysical optical parameters for clouds or aerosol. The cloud microphysical parameter retrieval uses radiances at visible $(0.6-0.8 \mu \mathrm{m})$, near-infrared $(1.6 \mu \mathrm{m})$, and infrared $(10.8-12.0 \mu \mathrm{m})$ wavelengths as a first step, whereas as a second step, the retrieval also uses the other channels to improve the accuracy of cloud parameters, because the other channels (for instance, the channels at $3.9 \mu \mathrm{m}$ ) can contain useful information on particular types of clouds. Retrieving aerosol properties from satellite observations over land can 
be difficult because of the surface reflection, complex aerosol composition and aerosol absorption. Nonetheless, since aerosols are highly variable in time and space, we prefer to use information retrieved at the same time and location of solar irradiance estimation, rather than from spatially distant ground measurements or temporally distant satellite retrievals derived from other platforms. Aerosol information retrieved by AMESIS has been validated through comparisons with MODIS and AERONET. Validation of cloud and aerosol microphysical properties has been reported in [19]. Subsequently, the model retrieves the surface solar irradiance on the basis of the correspondent look-up tables. The look-up tables are periodically updated in order to take into account albedo/emissivity variations. The update is typically performed once every 8 days. The model, therefore, incorporates the effects due to aerosol, overcast and partially cloudy coverage; the retrieval of surface temperature, total integrated water vapor, cloud and aerosol microphysical parameters is achieved by using the low spatial resolution VIS and IR SEVIRI channels, whereas surface solar irradiance is retrieved through the high spatial resolution HRV channel. If the HRV pixel is classified as clear, AMESIS model retrieves the correct coefficient from the correspondent look-up table according to albedo, integrated water vapor, solar zenith, azimuth solar-satellite angles, and the elevation above sea level. If the HRV and the IR/VIS pixels are classified as cloudy, the procedure starts to retrieve cloudy microphysical parameters. Depending on the cloud microphysical parameter information obtained from this first step, the surface irradiance is estimated by using the correspondent look-up table. If the HRV and the IR/VIS pixels are classified, respectively, as cloudy and partially cloudy, the procedure starts to retrieve cloudy microphysical parameters for partially cloudy cases according to the cloud fraction index. In the second step, the surface irradiance is estimated by using the correspondent look-up table for the cloud microphysical parameters. To evaluate the performances (in terms of run-time and accuracy), the AMESIS operational version gives two different estimated solar surface irradiance products, one using IR-VIS channels only (called SSI_VIS hereafter), the other also using the HRV channel (called SSI_HRV hereafter).

\section{Methodology}

The AMESIS SSI_VIS and SSI_HRV products are validated against the surface solar irradiance product from the ground pyranometer network (called SSI_Ground hereafter). Data from these three sources were treated in order to check data quality, to find space/time colocation, and finally to compute statistical scores.

The AMESIS surface solar irradiance products are co-located with the ground-based products in order to associate each satellite pixel with the corresponding surface solar irradiance values measured by ground-based pyranometers. The temporal co-location is obtained as follows.

The SEVIRI imaging phase takes twelve minutes for acquisition, and three minutes for calibration, retrace and stabilization. The knowledge of the pixel scan time relative to the initial time of the full disk scan cycle is necessary for co-locating satellite-derived products with ground-based measurements. The scan time (minutes) is calculated for each MSG SEVIRI scan line (the scan line is completed in less than a second)

$$
\Delta \mathrm{t}(\operatorname{lin})=\frac{\operatorname{lin}+\frac{\left(\operatorname{lin}_{\mathrm{sev}}-\operatorname{lin}_{\mathrm{tot}}\right)}{2}-1}{\operatorname{lin}_{\mathrm{sev}}} \cdot \mathrm{t}_{\mathrm{full}}
$$

where $\operatorname{lin}_{\text {sev }}$ and $\operatorname{lin}_{\text {tot }}$ indicate the number of SEVIRI and total lines, and $t_{\text {full }}=\operatorname{lin}_{\text {sev }} /(3 \cdot 100)$ is the full disk scan time in minutes, since 3 VIS/IR lines are scanned per MSG revolution and the MSG satellite rotates at 100 rotations per minute. Please note that the sensor has more lines than reported in the Level 1.5 image data: $\operatorname{lin}_{\text {sev }}=3750$ (11,250 for HRV) and lin $n_{\text {tot }}=3712$ (11,136 for HRV) [44].

An accurate georeferencing of satellite imagery is very important when computing the surface solar irradiance estimation for the monitoring of the incoming solar power to the PV power plants. To our knowledge, only few studies regarding the SEVIRI geometry accuracy have been reported in the open literature. An East-West image shift immediately after eclipse of up to 3 pixels with respect to the multispectral channels of Meteosat- 8 with $3 \mathrm{~km}$ nominal resolution has been reported [51]. A shift 
of up to 8 pixels to the North on the HRV images over Alpine areas using lakes as landmarks has been reported in [52]. Such accuracy for HRV navigation does not fully satisfy the accuracy requirements for photovoltaic monitoring. Thus, a weekly automatic routine was developed to correct the navigation of IR/VIS and HRV channels. The navigation is based on a coastline-matching algorithm using the SEVIRI solar channels (HRV, 0.6 and $0.8 \mu \mathrm{m}$ ). The navigation procedure is, thus, restricted to daytime operation and assumes that the misalignment is linear in both north/south and west/east directions. For navigation correction, clear images have been used in order to have $70 \%$ or more coastline edge pixels visible.

Each AMESIS product is associated with the scan time of the satellite overpass. Pyranometer surface solar irradiances measured every $10 \mathrm{~min}$ have been interpolated at scan time of the satellite overpass.

The validation of the AMESIS products against the ground-based reference products is performed through the assessment of statistical scores. In addition to the correlation coefficient, four different statistical scores, from among the most commonly used, are calculated. These are the mean bias error (MBE), root mean square error (RMSE), mean absolute error (MAE) and mean absolute percentage error (MAPE) computed as follows:

$$
\operatorname{corr}=\frac{\operatorname{cov}(p, s)}{\delta_{p} \delta_{s}}
$$

where $p$ denotes ground measured data, $s$ denotes satellite products, cov is the covariance, $\delta_{p}$ is the standard deviation of $p$ and $\delta_{s}$ is the standard deviation of $s$;

$$
\begin{gathered}
\text { MBE }=\frac{1}{n} \sum_{i=1}^{n}\left(s_{i}-p_{i}\right) \\
\operatorname{RMSE}=\left[\frac{1}{n} \sum_{i=1}^{n}\left(s_{i}-p_{i}\right)^{2}\right]^{1 / 2} \\
\text { MAE }=\frac{1}{n} \sum_{i=1}^{n}\left|s_{i}-p_{i}\right| \\
\text { MAPE }=\frac{100 \%}{n} \sum_{i=1}^{n}\left|\frac{\left(p_{i}-s_{i}\right)}{p_{i}}\right|
\end{gathered}
$$

\section{Results and Discussion}

From the data listed in Table 2, three datasets were derived (clear, cloudy and partially cloudy) by using cloud detection AMESIS modules for low (VIS) [31,49] and high spatial (HRV) [53] resolution. In the validation phase, we did not find features that could be related to geographic/altitude characteristics of ground-based stations. Conversely, the quality of the estimates seems to be mostly related to meteorological and albedo conditions, particularly the cloud/aerosol and surface emissivity values used. The pre-established LUTs have been calculated for different altitudes (0 to $3500 \mathrm{~m})$. The $\mathrm{min} / \mathrm{max}$ statistical scores obtained for each station in clear sky are 0.993/0.996 correlation coefficient, 2.33/3.95 W/m² MBE, 18.52/27.03 W/ $\mathrm{m}^{2} \mathrm{RMSE}$, and 2.36/9.28 W/m² MAE.

Table 2. Periods considered in the AMESIS validation.

\begin{tabular}{ccc}
\hline Year & Month & Days \\
\hline 2017 & June & 10 to 30 \\
2017 & October & 1 to 20 \\
2018 & March & 10 to 30 \\
\hline
\end{tabular}

The datasets were compared against ground observation data. 
Figures 2-4 show the surface solar irradiance estimated by AMESIS and measured by ground pyranometers for different days under different meteorological situations. For cloudy (Figure 3) and clear pixels (Figure 2) the AMESIS SSI_VIS and SSI_HRV products are comparable, while for partially covered sky (Figure 4), we can see how the SSI_HRV product is closer to the ground-measured data with respect to the SSI_VIS product. This is likely due to the fact that HRV, thanks to its resolution, better captures the weather conditions at the pyranometer site, especially in cloud-broken sky. At the same time, the HRV channel also exhibits a difference in mountainous areas, better capturing the sharp changes of albedo. The resolution of the other channels is low compared to the scale of peculiarities of the surface and broken clouds. Other authors have investigated the potential to increase the fraction of cloud-free observations by increasing sensor resolution. Particularly, some authors have also demonstrated that the relative gain in cloud-free observations as a function of sensor resolution depends on cloud coverage regions and seasons [54].
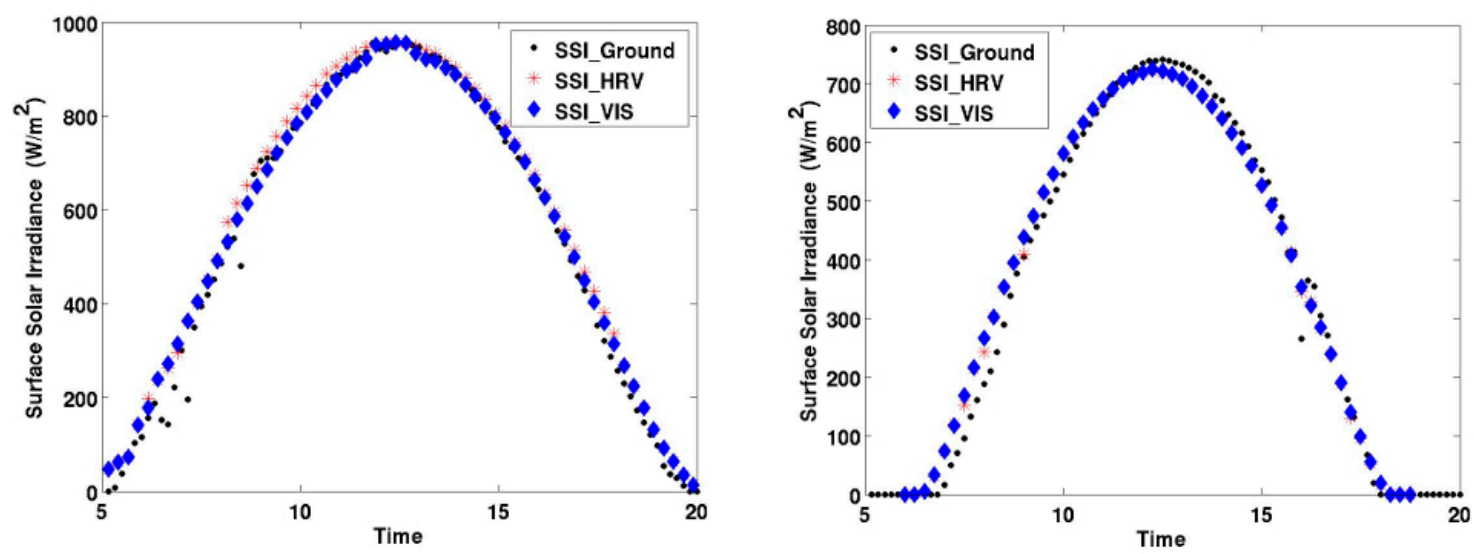

Figure 2. Surface solar irradiance estimated in clear sky by AMESIS, both SSI_HRV and SSI_VIS, and measurements by ground-based pyranometers. (Left column): 10 June 2017 (Lat $=45.269261$, Long = 9.5620594). (Right column): 14 March $2018($ Lat $=45.121067$, Long = 10.195482).
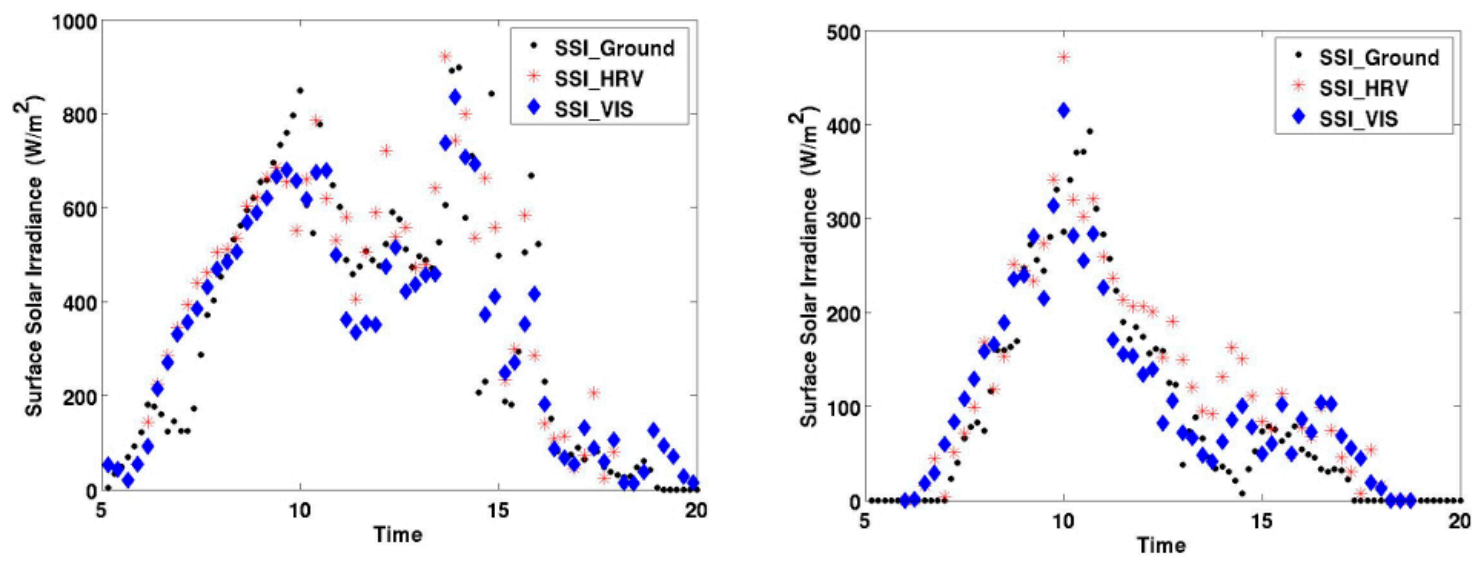

Figure 3. As in Figure 2, but for cloudy sky. (Left column): 15 June 2017 (Lat $=45.891499$, Long $=10.188790)$. (Right column): 18 March 2018 (Lat = 45.187836, Long = 10.887401). 

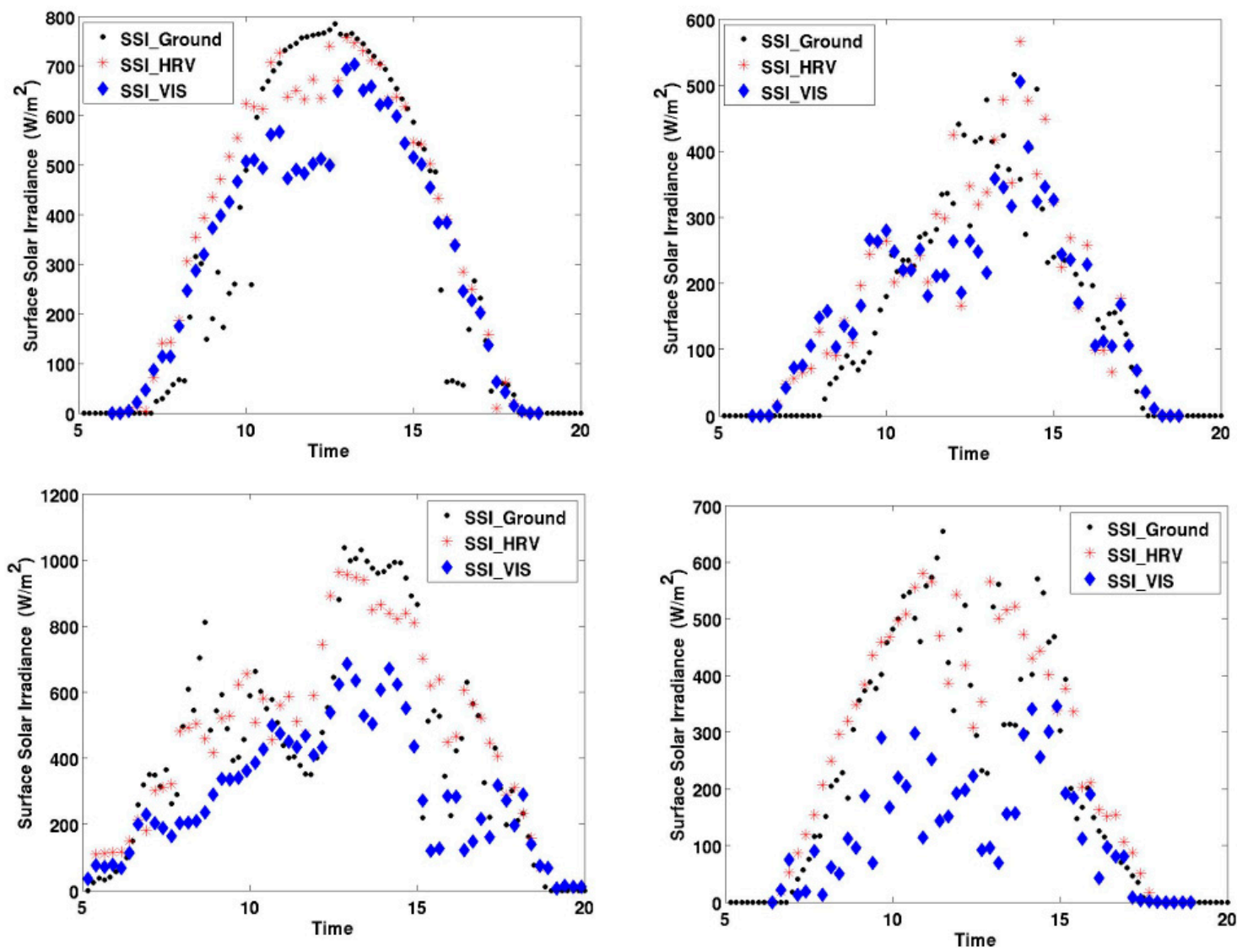

Figure 4. As in Figure 2, but for partially cloudy sky. First row; (Left column): 16 March 2018 $($ Lat $=46.105179$, Long = 9.5694208). (Right column): 12 March $2018($ Lat $=46.013573$, Long = 9.6624260). Second row; (Left column): 15 June 2017 (Lat = 45.633198, Long = 9.5564108). (Right column): 4 October 2017 (Lat $=45.715240$, Long $=9.6892786)$.

Tables 3 and 4 show the statistical analysis by means of the RMSE, MBE, MAE, MAPE and correlation coefficient. Figures 5-7 show the scatterplot of the irradiance derived from AMESIS compared against the ground-based measurements for clear, overcast and partially cloudy sky.

Table 3. Results of statistical assessment for the SSI_VIS product with respect to SSI_Ground. Units of the statistical scores are specified in the bracket. $\mathrm{N}$ indicates the number of used pixels.

\begin{tabular}{ccccccc}
\hline & $\mathbf{N}$ & CORR & MBE $\left(\mathbf{W} / \mathbf{m}^{\mathbf{2}}\right)$ & RMSE $\left(\mathbf{W} / \mathbf{m}^{\mathbf{2}}\right)$ & MAE $\left(\mathbf{W} / \mathbf{m}^{\mathbf{2}}\right)$ & MAPE \\
\hline Clear & 653 & 0.996 & 1.37 & 23.02 & 16.12 & 10.46 \\
Cloudy & 4564 & 0.969 & -2.92 & 49.95 & 36.47 & 24.31 \\
Partially cloudy & 4028 & 0.862 & -33.69 & 117.84 & 76.84 & 112.13 \\
\hline
\end{tabular}

Table 4. As in Table 2, but for the SSI_HRV product with respect to SSI_Ground.

\begin{tabular}{ccccccc}
\hline & $\mathbf{N}$ & CORR & MBE $\left(\mathbf{W} / \mathbf{m}^{\mathbf{2}}\right)$ & RMSE $\left(\mathbf{W} / \mathbf{m}^{\mathbf{2}}\right)$ & MAE $\left(\mathbf{W} / \mathbf{m}^{\mathbf{2}}\right)$ & MAPE \\
\hline Clear & 474 & 0.997 & 0.76 & 17.25 & 11.79 & 4.93 \\
Cloudy & 4558 & 0.968 & 0.86 & 53.88 & 41.91 & 33.07 \\
Partially cloudy & 4143 & 0.995 & 0.34 & 23.04 & 15.44 & 12.37 \\
\hline
\end{tabular}



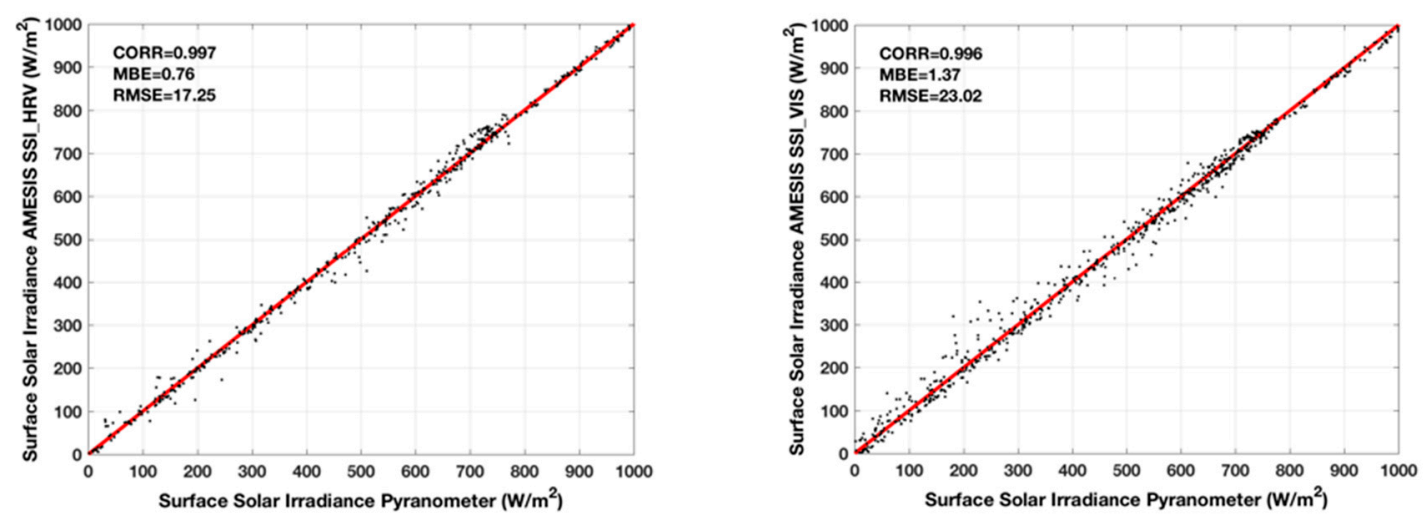

Figure 5. Scatterplot of the irradiance outputs derived from AMESIS compared against the ground-based irradiance for clear sky. (Left): SSI_HRV product, (right): SSI_VIS product.
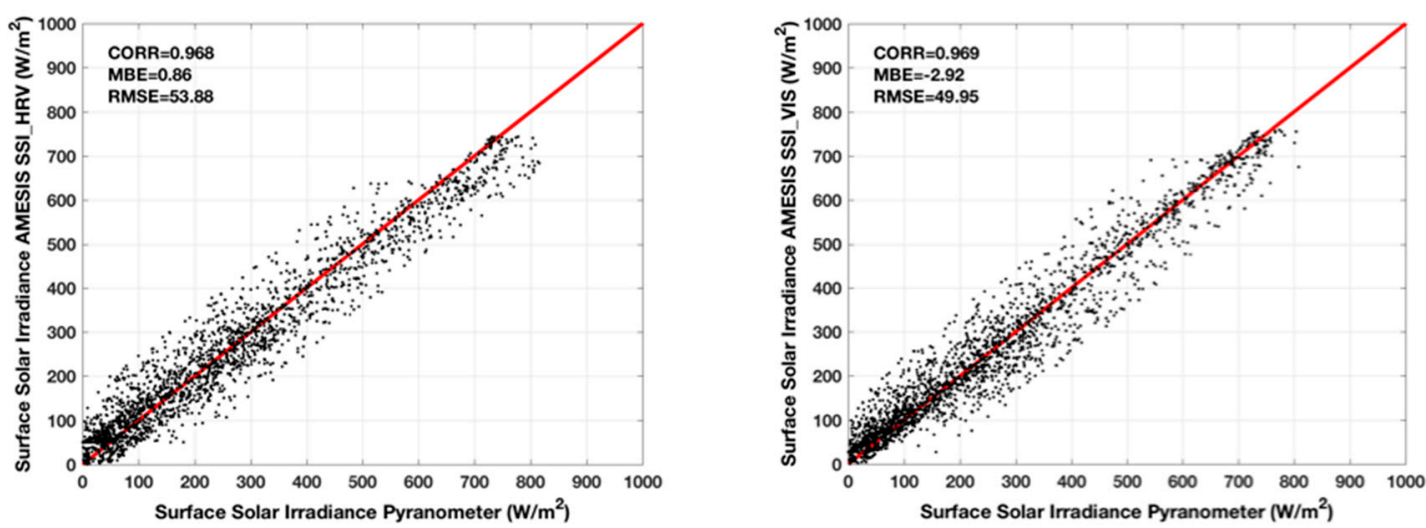

Figure 6. Same as Figure 5, but for cloudy sky. (Left): SSI_HRV product, (right): SSI_VIS product.
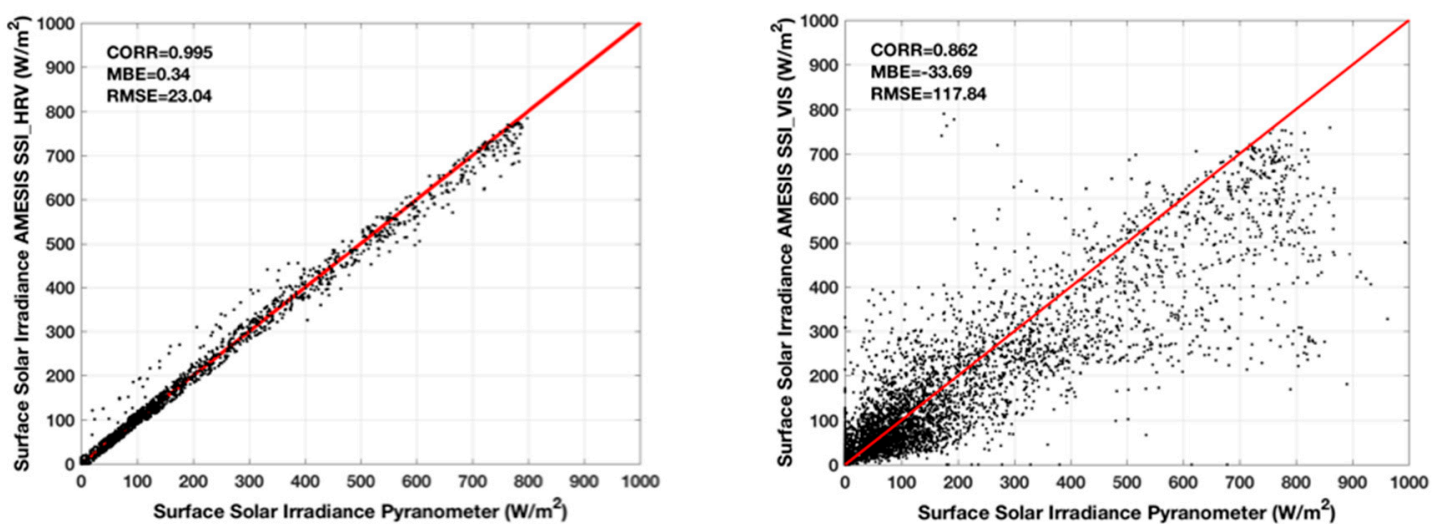

Figure 7. Same as Figure 5, but for partially cloudy sky. (Left): SSI_HRV product, (right): SSI_VIS product.

Small positive biases, of 1.30 and $0.76 \mathrm{~W} / \mathrm{m}^{2}$, respectively, for SSI_VIS and SSI_HRV, and correlation above 0.99 for both the products are found. This indicates, together with the other statistical scores, a very good agreement between AMESIS model and measurements for clear sky. For overcast cloudy sky, we found biases of -2.92 and $0.86 \mathrm{~W} / \mathrm{m}^{2}$, respectively, for SSI_VIS and SSI_HRV, and a correlation above 0.96 for both products. The RMSEs were 49.95 and $53.88 \mathrm{~W} / \mathrm{m}^{2}$, respectively, for SSI_VIS and SSI_HRV, indicating a good detection of clouds and an accurate estimation of their microphysical parameters, despite the limitations due to the SEVIRI low vertical resolution. The bias, 
RMSE, and correlation coefficients from the comparison with ground-based measurements show that AMESIS provides cloudy sky products that are generally as accurate as other methods of similar a kind. A large negative bias of $-33.69 \mathrm{~W} / \mathrm{m}^{2}$ and a correlation of 0.862 were found for SSI_VIS for partially cloudy sky. Dramatic improvements (bias $0.34 \mathrm{~W} / \mathrm{m}^{2}$ and 0.995 correlation) were found for SSI_HRV. This indicates that HRV is able to detect clear area contained within the largest pixel of low spatial resolution SEVIRI channels. Also, the RMSE is much larger for SSI_VIS $\left(117.84 \mathrm{~W} / \mathrm{m}^{2}\right)$ than for SSI_HRV $\left(23.04 \mathrm{~W} / \mathrm{m}^{2}\right)$. The RMSE in all cases is slightly higher than the MAE, except for VIS partially cloudy data; this means that there are values quite different from the measured ones. In fact, as seen from Figure 7, and also from the MBE value, the SSI_VIS often underestimates the measured values. The HRV channel is very useful for analyzing low-resolution pixels and estimating the fraction of the pixels covered with clouds. Additionally, MAPE values can be seen as acceptable, with the lowest value being found for the clear HRV dataset. The analysis of statistical scores suggests that the HRV channel, or more generally, a higher-resolution sensor, can improve the estimation of solar irradiance over partially cloudy sky. In the evaluation of the performances under different sky conditions, the statistical scores were also compared to those given by the validation of 4 different papers cited in the introduction. The first and the second [11,22] were selected because they report the statistics for different weather conditions and different satellite platforms; the third [42] was considered because it uses the HRV channel, whereas the fourth [2] is based on MSG/SEVIRI and reports on the validation against some alpine stations. The statistical scores reported in [11] for two different stations in clear sky are (min/max): 0.77/0.86 correlation coefficient, 47.80/-22.29 W/ $\mathrm{m}^{2} \mathrm{MBE}$ and $191.81 / 140.77 \mathrm{~W} / \mathrm{m}^{2}$ RMSE. For cloudy sky, the statistical scores are 0.74/0.84 correlation coefficient, 80.66/40.31 W/m² MBE and 193.79/151.24 W/m² RMSE. The results of the comparison in [22] based on seven pyranometers showed that the estimated surface irradiance agreed with ground measurements with correlation coefficients of $0.94,0.69$, and 0.89 , a bias of $26.4 \mathrm{~W} / \mathrm{m}^{2},-5.9 \mathrm{~W} / \mathrm{m}^{2}$, and $14.9 \mathrm{~W} / \mathrm{m}^{2}$ for clear-sky, cloudy sky, and all-sky conditions, respectively. The root mean square errors (RMSEs) of surface solar irradiance were $80.0 \mathrm{~W} / \mathrm{m}^{2}(16.8 \%), 127.6 \mathrm{~W} / \mathrm{m}^{2}(55.1 \%)$, and $99.5 \mathrm{~W} / \mathrm{m}^{2}(25.5 \%)$ for clear sky, cloudy sky (overcast sky and partly cloudy sky), and all sky (clear-sky and cloudy-sky) conditions, respectively. The $\mathrm{min} / \mathrm{max}$ statistical scores reported in [42] for the different seasons are 0.94/0.98 correlation coefficient, $-7.46 / 13.31 \mathrm{~W} / \mathrm{m}^{2} \mathrm{MBE}, 64.25 / 97.23 \mathrm{~W} / \mathrm{m}^{2} \mathrm{RMSE}$. The last one [2], discussing the HelioMont model based on MSG/SEVIRI, reports the statistical scores for three alpine stations. The $\mathrm{min} / \mathrm{max}$ statistical scores reported are $20 / 40 \mathrm{~W} / \mathrm{m}^{2} \mathrm{MAE},-5 / 17 \mathrm{MBE} \mathrm{W} / \mathrm{m}^{2}$ for clear sky, while $49 / 72 \mathrm{~W} / \mathrm{m}^{2} \mathrm{MAE},-17 /-8 \mathrm{~W} / \mathrm{m}^{2} \mathrm{MBE}$ are reported for cloudy sky. In the HelioMont model, correction methods are also implemented to account for the effects of topography, such as shadowing, reflection, local horizon elevation angle and sky view factor. All these statistical scores, compared with those obtained using AMESIS model (Table 4), suggest that our proposed method can successfully estimate surface solar irradiance and yields similar or sometimes better performances. Obviously, in order to properly evaluate the performances of the models it would be necessary to consider the same ground-data set. Concerning processing time, it may be useful to separate the process into two steps. During the first step, HRV calibration, navigation, co-location and cloud mask run simultaneously with VIS and IR channel processes (calibration, navigation, cloud detection and classification, aerosol and cloud microphysical parameter retrievals) and, therefore, HRV processing does not add significant delay to the low channel processing chain. During the second step, i.e., the final estimation of SSI, the HRV processing takes longer than the VIS processing by a factor of five. More precisely, the operative chain process 1,415,088 HRV pixels and 79,616 low-resolution pixels centered in Italy. The runtime is $3.48 \mathrm{~min}$ to estimate the SSI_VIS product, while it is 4.48 min for the SSI_HRV product. The processes were run on a server with 2 x Intel Xeon Gold 6132 2.6 GHz RAM 256 GB DDR4-2667MT/S. 


\section{Conclusions}

The AMESIS model was developed at the Institute of Methodologies for Environmental Analysis of the National Research Council of Italy (IMAA-CNR) in order to infer surface solar irradiance from a SEVIRI radiometer on board the MSG geostationary satellite. The operational version of the AMESIS model has been running continuously at IMAA-CNR over all Italy for a year in order to estimate the accuracy of the continuous monitoring from space in comparison with real PV energy inputs and outputs within the framework of the SolarCloud project. This paper shows the difference between the two AMESIS products (SSI_VIS and SSI_HRV) against simultaneous ground-based observations from a network of 63 pyranometers for different sky conditions (clear, overcast and partially clear). Regarding the impact on PV systems, a dedicated field campaign is ongoing; the in-depth analysis will be the subject of future work. For clear conditions, both products are very accurate; indeed, a small positive bias of 1.37 and $0.76 \mathrm{~W} / \mathrm{m}^{2}$, respectively, for SSI_VIS and SSI_HRV, and a correlation above 0.99 for both products, was found. For overcast cloudy sky, we found biases of -2.92 and $0.86 \mathrm{~W} / \mathrm{m}^{2}$, respectively, for SSI_VIS and SSI_HRV, and a correlation above 0.96 for both products. A large negative bias, $-33.69 \mathrm{~W} / \mathrm{m}^{2}$, and a correlation of 0.862 were found for SSI_VIS for partially cloudy sky, whereas a bias of $0.34 \mathrm{~W} / \mathrm{m}^{2}$ and a correlation value of 0.995 were found for SSI_HRV. This indicates that solar resource monitoring requires footprints that minimize the effect of clouds. The HRV channel is able to detect clear areas contained within the larger pixels of low spatial resolution SEVIRI channels, thus providing more accurate surface solar irradiance, while the SSI_VIS product underestimates the surface solar irradiance due to its lower resolution. During the first step, HRV processing does not add significant delay to the low channel processing chain. During the second step, i.e., the final estimation of SSI, the HRV processing takes longer than the VIS processing by a factor of five, due to the greater number of pixels to consider. To evaluate the AMESIS performance, our statistical scores were compared against those obtained in [2,11,22,42]; this comparison suggests that our proposed AMESIS model (SSI_HRV) can successfully estimate surface solar irradiance and yields similar or sometimes better performances. This confirms that the HRV channel, or more generally, a higher-resolution sensor, can improve the estimation of solar irradiance over partially cloudy sky.

Author Contributions: F.R., D.C., E.R. (Elisabetta Ricciardelli) and E.G., designed the research, wrote the paper and contributed to evaluation process. D.G., F.D.P., S.G., A.C., S.T.N., E.R. (Ermann Ripepi), S.L., and M.V. contributed to data processing. All the co-authors helped to revise the manuscript.

Funding: This work has been financed by the Italian Ministry of Economic Development (MISE) in the framework of the SolarCloud project, contract No. B01/0771/04/X24.

Conflicts of Interest: The authors declare no conflict of interest. The founding sponsors had no role in the design of the study; in the collection, analyses, or interpretation of data; in the writing of the manuscript, and in the decision to publish the results.

\section{References}

1. Roupioz, L.; Jia, L.; Nerry, F.; Menenti, M. Estimation of daily solar radiation budget at kilometer resolution over the Tibetan Plateau by integrating MODIS data products and a DEM. Remote Sens. 2016, 8, 504. [CrossRef]

2. Castelli, M.; Stöckli, R.; Zardi, D.; Tetzlaff, A.; Wagner, J.E.; Belluardo, G.; Zebisch, M.; Petitta, M. The HelioMont method for assessing solar irradiance over complex terrain: Validation and improvements. Remote Sens. Environ. 2014, 152, 603-613. [CrossRef]

3. BWielicki, B.; Cess, R.D.; King, M.D.; Randall, D.A.; Harrison, E.F. Mission to planet Earth: Role of clouds and radiation in climate. Bull. Am. Meteorol. Soc. 1995, 76, 2125-2153. [CrossRef]

4. Iqbal, M. An Introduction to Solar Radiation; Academic Press: Cambridge, MA, USA, 1983.

5. Perez, R.; Seals, R.; Zelenka, A. Comparing satellite remote sensing and ground network measurements for the production of site/time specific irradiance data. Sol. Energy 1997, 60, 89-96. [CrossRef]

6. Zelenka, A.; Czeplak, G.; D’Agostino, V.; Josefson, W.; Maxwell, E.; Perez, R. Techniques for Supplementing Solar Radiation Network Data; International Energy Agency: Paris, France, 1992. 
7. Mueller, R.; Behrendt, T.; Hammer, A.; Kemper, A. A New Algorithm for the Satellite-Based Retrieval of Solar Surface Irradiance in Spectral Bands. Remote Sens. 2012, 4, 622-647. [CrossRef]

8. Deneke, H.M.; Feijt, A.J.; Roebeling, R.A. Estimating surface solar irradiance from METEOSAT SEVIRI-derived cloud properties. Remote Sens. Environ. 2008, 112, 3131-3141. [CrossRef]

9. Qu, Z.; Gschwind, B.; Lefèvre, M.; Wald, L. Improving HelioClim-3 estimates of surface solar irradiance using the McClear clear-sky model and recent advances in atmosphere composition. Atmos. Meas. Tech. 2014, 7, 3927-3933. [CrossRef]

10. Journée, M.; Bertrand, C. Improving the spatio-temporal distribution of surface solar radiation data by merging ground and satellite measurement. Remote Sens. Environ. 2010, 114, 2692-2704. [CrossRef]

11. Xia, S.; Mestas-Nuñez, A.M.; Xie, H.; Vega, R. An Evaluation of Satellite Estimates of Solar Surface Irradiance Using Ground Observations in San Antonio, Texas, USA. Remote Sens. 2017, 9, 1268. [CrossRef]

12. Antonanzas-Torres, F.; Martínez de Pisón, F.J.; Antonanzas, J.; Perpiñán, O. Downscaling of global solar irradiation in complex areas in R. J. Renew. Sustain. Energy 2014, 6, 063105. [CrossRef]

13. Bessafi, M.; Oree, V.; Khoodaruth, A.; Jumaux, G.; Bonnardot, F.; Jeanty, P.; Delsaut, M.; Chabriat, J.-P.; Dauhoo, M.Z. Downscaling solar irradiance using DEM-based model in young volcanic islands with rugged topography. Renew. Energy 2018, 126, 584-593. [CrossRef]

14. Journée, M.; Bertrand, C. Geostatistical merging of ground-based and satellite-derived data of surface solar radiation. Adv. Sci. Res. 2011, 6, 1-5. [CrossRef]

15. Wang, H.M.; Pinker, R.T. Shortwave radiative fluxes from MODIS: Model development and implementation. J. Geophys. Res. 2009, 114. [CrossRef]

16. Huang, G.; Liu, S.; Liang, S. Estimation of net surface shortwave radiation from MODIS data. Int. J. Remote Sens. 2012, 33, 804-825. [CrossRef]

17. Sun, Z.; Liu, J.; Zeng, X.; Liang, H. Parameterization of instan-taneous global horizontal irradiance: Cloudy-sky component. J. Geophys. Res. 2012, 117. [CrossRef]

18. Mueller, R.; Matsoukas, C.; Gratzki, A.; Behr, H.; Hollmann, R. The CM-SAF operational scheme for the satellite based retrieval of solar surface irradiance-A LUT based eigenvector hybrid approach. Remote Sens. Environ. 2009, 113, 1012-1024. [CrossRef]

19. Geraldi, E.; Romano, F.; Ricciardelli, E. An Advanced Model for the Estimation of the Surface Solar Irradiance Under All Atmospheric Conditions Using MSG/SEVIRI Data. IEEE Trans. Geosci. Remote Sens. 2012, 50, 2934-2953. [CrossRef]

20. Lu, N.; Liu, R.; Liu, J.; Liang, S. An algorithm for estimating downward shortwave radiation from GMS 5 visible imagery and its evaluation over China. J. Geophys. Res. 2010, 115. [CrossRef]

21. Huang, G.; Ma, M.; Liang, S.; Liu, S.; Li, X. A LUT-based approach to estimate surface solar irradiance by combining MODIS and MTSAT data. J. Geophys. Res. 2011, 116. [CrossRef]

22. Zhang, H.; Huang, C.; Yu, S.; Li, L.; Xin, X.; Liu, Q. A Lookup-Table-Based Approach to Estimating Surface Solar Irradiance from Geostationary and Polar-Orbiting Satellite Data. Remote Sens. 2018, 10, 411. [CrossRef]

23. Hammer, A.; Heinemann, D.; Hoyer, C.; Lorenz, E.; Muller, R.; Beyer, H.G. Solar energy assessment using remote sensing technologies. Remote Sens. Environ. 2003, 86, 423-432. [CrossRef]

24. Rigollier, C.; Lefèvre, M.; Wald, L. The method Heliosat-2 for deriving shortwave solar radiation from satellite images. Sol. Energy 2004, 77, 159-169. [CrossRef]

25. Posselt, R.; Mueller, R.; Stöckli, R.; Trentmann, J. Remote sensing of solar surface radiation for climate monitoring-The CM-SAF retrieval in international comparison. Remote Sens. Environ. 2012, 118, 186-198. [CrossRef]

26. Linares-Rodriguez, A.; Ruiz-Arias, J.A.; Pozo-Vazquez, D.; Tovar-Pescador, J. An artificial neural network ensemble model for estimating global solar radiation from Meteosat satellite images. Energy 2013, 61, 636-645. [CrossRef]

27. Antonanzas-Torres, F.; Urraca, R.; Antonanzas, J.; Fernandez-Ceniceros, J.; Martinez-de-Pison, F.J. Generation of daily global solar irradiation with support vector machines for regression. Energy Convers. Manag. 2015, 96, 277-286. [CrossRef]

28. Zou, L.; Wang, L.; Lin, A.; Zhu, H.; Peng, Y.; Zhao, Z. Estimation of global solar radiation using an artificial neural network based on an interpolation technique in southeast China. J. Atmos. Sol. Terr. Phys. 2016, 146, 110-122. [CrossRef] 
29. Tang, W.; Qin, J.; Yang, K.; Liu, S.; Lu, N.; Niu, X. Retrieving high-resolution surface solar radiation with cloud parameters derived by combining MODIS and MTSAT data. Atmos. Chem. Phys. 2016, 16, 2543-2557. [CrossRef]

30. Romano, F.; Cimini, D.; Nilo, S.T.; Di Paola, F.; Ricciardelli, E.; Ripepi, E.; Viggiano, M. The Role of Emissivity in the Detection of Arctic Night Clouds. Remote Sens. 2017, 9, 406. [CrossRef]

31. Ricciardelli, E.; Romano, F.; Cuomo, V. Physical and statistical approaches for cloud identification usingMeteosat Second Generation-Spinning Enhanced Visible and Infrared Imager Data. Remote Sens. Environ. 2008, 112, 2741-2760. [CrossRef]

32. Reuter, M.; Thomas, W.; Albert, P.; Lockhoff, M.; Weber, R.; Karlsson, K.G.; Fischer, J. The CM-SAF and FUB Cloud Detection Schemes for SEVIRI: Validation with Synoptic Data and Initial Comparison with MODIS and CALIPSO. J. Appl. Meteorol. Climatol. 2009, 48, 301-316. [CrossRef]

33. Derrien, M.; Le Gléau, H. MSG/SEVIRI cloud mask type from SAFNWC. Int. J. Remote Sens. 2005, 26, 4707-4732. [CrossRef]

34. Bley, S.; Deneke, H. A Threshold-based cloud mask for the high-resolution visible channel of Meteosat second generation SEVIRI. Atmos. Meas. Tech. 2013, 6, 2713-2723. [CrossRef]

35. Ackerman, S.A.; Strabala, K.I.; Menzel, W.P.; Frey, R.A.; Moeller, C.C.; Gumley, L.E. Discriminating clear sky from clouds with MODIS. J. Geophys. Res. 1998, 103, 132-141. [CrossRef]

36. Hocking, J.; Francis, P.N.; Saunders, R. Cloud detection in Meteosat Second Generation imagery at the Met Office. Meteorol. Appl. 2011, 18, 307-323. [CrossRef]

37. Amato, U.; Antoniadis, A.; Cuomo, V.; Cutillo, L.; Franzese, M.; Murino, L.; Serio, C. Statistical cloud detection from SEVIRI multispectral images. Remote Sens. Environ. 2008, 112, 750-766. [CrossRef]

38. Asmala, A.; Shaun, Q. Cloud masking for remotely sensed data using spectral and principal components analysis. ETASR Eng. Technol. Appl. Sci. Res. 2012, 2, 221-225.

39. Nair, M.S.; Lakshmanan, R.; Wilscy, M.; Tatavarti, R. Fuzzy logic-based automatic contrast enhancement of satellite images of ocean. Signal Image Video Process. 2011, 5, 69-80. [CrossRef]

40. Bose, A.; Mali, K. Fuzzy-based artificial bee colony optimization for gray image segmentation. Signal Image Video Proc. 2016, 10, 1089-1096. [CrossRef]

41. Boulifa, M.; Adane, A.; Rezagui, A.; Ameur, Z. Estimate of the Global Solar Radiation by Cloudy Sky Using HRV Images. Energy Proc. 2015, 74, 1079-1089. [CrossRef]

42. Bouchouicha, K.; Razagui, A.; Bachari, N.E.I.; Aoun, N. Estimation of Hourly Global Solar Radiation Using MSG-HRV images. Int. J. Appl. Environ. Sci. 2016, 11, 351-368, ISSN 0973-6077. Available online: https:/ / www.ripublication.com/ijaes16/ijaesv11n2_01.pdf (accessed on 27 July 2018).

43. Hammer, A.; Kühnert, J.; Weinreich, K.; Lorenz, E. Short-Term Forecasting of Surface Solar Irradiance Based on Meteosat-SEVIRI Data Using a Nighttime Cloud Index. Remote Sens. 2015, 7, 9070-9090. [CrossRef]

44. Schmetz, J.; Pili, P.; Tjemkes, S.; Just, D.; Kerkmann, J.; Rota, S.; Ratier, A. An Introduction to Meteosat second generation (MSG). Bull. Am. Meteorol. Soc. 2002, 83, 977-992. [CrossRef]

45. Gallucci, D.; Romano, F.; Cersosimo, A.; Cimini, D.; Di Paola, F.; Gentile, S.; Geraldi, E.; Larosa, S.; Nilo, S.T.; Ricciardelli, E.; et al. Nowcasting Surface Solar Irradiance with AMESIS via Motion Vector Fields of MSG-SEVIRI Data. Remote Sens. 2018, 10, 845. [CrossRef]

46. Steinacker, R.; Haberli, C.; Pottschacher, W. A transparent method for the analysis quality evaluation of irregularly distributed noisy observational data. J. Appl. Meteorol. 2000, 12, 2303-2316. [CrossRef]

47. Lussana, C.; Uboldi, F.; Salvati, M.R. A spatial consistency test for surface observations from mesoscale meteorological networks. Q. J. R. Meteorol. Soc. 2010, 136, 1075-1088. [CrossRef]

48. Romano, F.; Ricciardelli, E.; Cimini, D.; Di Paola, F.; Viggiano, M. Dust Detection and Optical Depth Retrieval Using MSG-SEVIRI Data. Atmosphere 2013, 4, 35-47. [CrossRef]

49. Ricciardell, E.; Cimini, D.; Di Paola, F.; Romano, F.; Viggiano, M.A. A statistical approach for rain intensity differentiation using Meteosat Second Generation-Spinning enhanced visible and infrared imager observations. Hidrol. Earth Syst. Sci. 2014, 18, 2559-2576. [CrossRef]

50. Mace, G.G.; Zhang, Q. The CloudSat radar-lidar geometrical profile product (RL-GeoProf): Updates, improvements, and selected results. J. Geophys. Res. Atmos. 2014, 119. [CrossRef]

51. Hanson, C.; Mueller, J. Status of the SEVIRI Level 1.5 Data. In Proceedings of the Second MSG RAO Workshop (ESA SP-582, November 2004), Salzburg, Austria, 9-10 September 2004; Available online: http: / / earth.esa.int/workshops/msg_rao_2004/papers/4_hanson.pdf (accessed on 24 June 2018). 
52. Dürr, B.; Zelenka, A. Deriving surface global irradiance over the Alpine region from Meteosat Second Generation by supplementing the HELIOSAT method. Int. J. Remote Sens. 2009, 30, 5821-5841. [CrossRef]

53. Nilo, S.T.; Romano, F.; Cermak, J.; Cimini, D.; Ricciardelli, E.; Cersosimo, A.; Di Paola, F.; Gallucci, D.; Gentile, S.; Geraldi, E.; et al. Fog Detection Based on Meteosat Second Generation-Spinning Enhanced Visible and InfraRed Imager High Resolution Visible Channel. Remote Sens. 2018, 10, 541. [CrossRef]

54. Krijger, J.M.; van Weele, M.; Aben, I.; Frey, R. Technical Note: The effect of sensor resolution on the number of cloud-free observations from space. Atmos. Chem. Phys. 2007, 7, 2881-2891. [CrossRef]

(C) 2018 by the authors. Licensee MDPI, Basel, Switzerland. This article is an open access article distributed under the terms and conditions of the Creative Commons Attribution (CC BY) license (http:/ / creativecommons.org/licenses/by/4.0/). 